\title{
microRNA-223 Deficiency Exacerbates Acute Inflammatory Response to Monosodium Urate Crystals by Targeting NLRP3
}

\author{
Qi-Bin Yang ${ }^{1,2}$ \\ Ling-Qin $\mathrm{Li}^{1}$ \\ Quan-Bo Zhang 2,3 \\ Yong-Long $\mathrm{He}^{1}$ \\ Qing-Sheng $\mathrm{Mi}^{2}$ \\ Jing-Guo Zhou ${ }^{4}$
}

'Department of Rheumatology and Immunology, Affiliated Hospital of North Sichuan Medical College, Nanchong, 637000, Sichuan Province, People's Republic of China; ${ }^{2}$ Henry Ford Immunology Program, Departments of Dermatology and Internal Medicine, Henry Ford Health System, Detroit, MI, 48202, USA; ${ }^{3}$ Department of Gerontology, Affiliated Hospital of North Sichuan Medical College, Nanchong, 637000, Sichuan Province, People's Republic of China; ${ }^{4}$ Department of Rheumatology and Immunology, Clinical Medical College and The First Affiliated Hospital of Chengdu Medical College, Chengdu, 610500, Sichuan Province, People's Republic of China
Correspondence: Qing-Sheng Mi Henry Ford Immunology Program, Departments of Dermatology and Internal Medicine, Henry Ford Health System, I Ford Place, Detroit, MI, 48202, USA

Tel + I-313-876-I0I7

Email qmil@hfhs.org

Jing-Guo Zhou

Department of Rheumatology and Immunology, Clinical Medical College and the First Affiliated Hospital of Chengdu Medical College, Chengdu, 610500,

Sichuan Province, People's Republic of China

Tel +86-28-830I-6078

Email jgzhou@cmc.edu.cn
Objective: MicroRNAs were identified as master-switch molecules limiting acute inflammatory response. This study investigated the potential role of microRNA (miR)-223 in the mechanism of gout.

Methods: Wild-type (WT) and miR-223 knock-out (KO) mice were used to evaluate the phenotypes of gout models. Inflammatory cytokines were measured in air pouch and peritoneal cavity lavage fluid. In addition to miR-223 level in gout patients, miR-223 and pro-inflammatory genes were examined in bone marrow-derived macrophages (BMDMs) from mice as well as peripheral blood mononuclear cells from healthy controls (HC) treated with monosodium urate (MSU) crystals in vitro.

Results: MiR-223 was up-regulated in the early phase in BMDMs from WT mice after MSU challenge and decreased rapidly, and this was not observed in miR-223 $\mathrm{KO}$ mice in vitro. In addition, miR-223 was required for macrophages homeostasis. In comparison with WT mice in vivo, miR-223 deficiency exacerbated swelling index of MSU-induced inflammation in foot pad and ankle joint models. MiR-223 deficiency also markedly aggravated inflammatory cells infiltration and cytokines release including interleukin (IL)-1 $\beta$, IL-6 and monocyte chemotactic protein-1 (MCP-1) in the air pouch and peritonitis models. In the in vitro experiments, miR-223 deficiency promoted the inflammatory response by targeting NLR family pyrin domain containing protein 3 (NLRP3). Besides, miR-223 level was downregulated in gout patients and in $\mathrm{HC}$ exposed to MSU in vitro.

Conclusion: MiR-223 was down-regulated in gout patients and miR-223 deficiency exacerbated inflammatory response in diverse murine models, suggesting that upregulation of miR-223 could be a potential therapeutic strategy for alleviating gouty inflammation.

Keywords: miR-223, gout, animal models, cytokines, monosodium urate

\section{Introduction}

Gout is an auto-inflammatory disease caused by the accumulation of monosodium urate (MSU) crystals in joints and connective tissues causing an intense inflammatory response and joint dysfunction. Recurrent attacks and spontaneous remission are typical clinical characteristics of acute gouty arthritis, which are important in the differential diagnosis of gouty arthritis from other types of arthritis. Currently, an acute gout attack is mediated by interleukin (IL)-1 $\beta$, which is central to the initiation of acute arthritis and is produced due to activation of Toll-like receptor 4 (TLR4)/nuclear factor (NF)- $\mathrm{B}$ and NLR 
family pyrin domain containing protein 3 (NLRP3) inflammasome signaling pathways by MSU crystals. ${ }^{1-6}$ However, the key regulatory mechanisms related to gouty inflammation have yet to be clarified.

MicroRNAs are a class of small, endogenous non-coding RNAs of approximately 20 nucleotides (nt) in length that regulate gene expression post-transcriptionally by binding to 3'-untranslated regions (UTRs), coding sequences or 5'UTRs of target messenger RNAs (mRNAs) and lead to inhibition of translation or mRNA degradation. ${ }^{7,8}$ MicroRNAs control the expression of genes involved in several biological processes such as apoptosis, proliferation, differentiation and metastasis. ${ }^{7,8}$ In addition, several microRNAs have been identified to be negative regulators of inflammation. ${ }^{9,10}$ One recent study has shown that microRNA-223 (miR-223) acts as a negative regulator of NLRP3 inflammasome activity in vitro. ${ }^{11}$ Given that miR223 is a negative regulator of NLRP3, and that NLRP3 is important for MSU-induced inflammation, ${ }^{12,13}$ we hypothesized that the loss of miR-223 may exacerbate the inflammatory response to MSU crystals.

In this study, miR-223 level was analyzed in gout patients and diverse phenotypes of MSU-induced gout murine models, including ankle arthritis, foot pad arthritis, subcutaneous air pouch and peritoneal cavity models, were evaluated in miR-223 knockout (KO) and wild-type (WT) mice in vivo. In addition, the targeting gene of miR-223 for regulating gouty inflammation was confirmed in bone marrow-derived macrophages (BMDMs) in vitro.

\section{Materials and Methods}

\section{Patients}

A total of 243 male patients with primary gout visited the Department of Rheumatology of the Affiliated Hospital of North Sichuan Medical College, China. These patients were confirmed to have primary gout according to the American College of Rheumatology classification criteria (1977) ${ }^{14}$ and were divided into acute gout (AG, 140 cases) and intercritical gout (IG, 103 cases) according to their clinical manifestations and C-reactive protein or erythrocyte sedimentation rate. Patients with gout had no history of cancer, hematopathy, nephropathy, infection or other autoimmune diseases, and did not receive any systemic anti-inflammatory treatments or medications to control the production and elimination of uric acid before the blood samples were obtained. Medical history and clinical data were obtained from all patients (Table 1). One hundred age-matched males who underwent regular physical examination during the same periods were enrolled as healthy controls (HC). They have no personal or familial history of gout and any systemic inflammatory diseases. In addition, routine blood counts and laboratory biochemical examinations of conventional parameters were normal. All participants in this study were from the Chinese Han population. The study was approved by the institutional research ethics committee of Affiliated Hospital of North Sichuan Medical College and written informed consent was obtained from each subject. Experiments using human blood were performed in accordance with the Declaration of Helsinki (No:2021ER(A)033).

Table I Comparison of Laboratory Indexes in Patients with Acute Gout, Intercritical Gout and Healthy Controls

\begin{tabular}{|c|c|c|c|c|c|}
\hline Laboratory Indexes & AG Group $(n=\mid 40)$ & IG Group $(n=103)$ & HC Group $(n=100)$ & $F / t$ value & p value \\
\hline $\mathrm{WBC}\left(\times 10^{9} / \mathrm{L}\right)$ & $8.9 \pm 3.2$ & $7.0 \pm 2.5$ & $5.9 \pm 1.4$ & 18.1 & $<0.001$ \\
\hline $\mathrm{GR}\left(\times 10^{9} / \mathrm{L}\right)$ & $6.1 \pm 2.9$ & $4.6 \pm 2.1$ & $3.3 \pm 1.0$ & 21.4 & $<0.001$ \\
\hline $\operatorname{ESR}(\mathrm{mm} / \mathrm{h})$ & $22.4 \pm 13.5$ & $14.2 \pm 7.4$ & - & 1.8 & 0.188 \\
\hline $\mathrm{UA}(\mu \mathrm{mol} / \mathrm{L})$ & $475.7 \pm 110.4$ & $469.4 \pm 77.4$ & $323.2 \pm 47.4$ & 36.6 & $<0.001$ \\
\hline $\mathrm{GLOB}(\mathrm{g} / \mathrm{L})$ & $31.9 \pm 5.2$ & $31.3 \pm 5.0$ & $28.3 \pm 3.3$ & 10.1 & $<0.001$ \\
\hline $\mathrm{TG}(\mathrm{mmol} / \mathrm{L})$ & $2.5 \pm 1.4$ & $2.1 \pm 0.8$ & $1.3 \pm 0.6$ & 17.7 & $<0.001$ \\
\hline $\mathrm{HDLC}(\mathrm{mmol} / \mathrm{L})$ & $1.0 \pm 0.2$ & $1.0 \pm 0.2$ & $1.4 \pm 0.4$ & 15.7 & $<0.001$ \\
\hline $\mathrm{TC}(\mathrm{mmol} / \mathrm{L})$ & $5.0 \pm 1.1$ & $5.1 \pm 0.7$ & $4.7 \pm 0.7$ & 2.4 & 0.096 \\
\hline $\operatorname{LDLC}(\mathrm{mmol} / \mathrm{L})$ & $2.7 \pm 0.7$ & $2.7 \pm 0.6$ & $2.5 \pm 0.7$ & 0.8 & 0.472 \\
\hline $\operatorname{VLDL}(\mathrm{mmol} / \mathrm{L})$ & $1.3 \pm 0.8$ & $1.2 \pm 0.6$ & $0.7 \pm 0.3$ & 15.5 & $<0.001$ \\
\hline apoAI (g/L) & $1.03 \pm 0.24$ & $1.2 \pm 0.21$ & $1.3 \mathrm{I} \pm 0.20$ & 11.4 & $<0.001$ \\
\hline apoB $100(g / L)$ & $0.85 \pm 0.19$ & $0.90 \pm 0.25$ & $0.7 I \pm 0.2 I$ & 3.6 & 0.042 \\
\hline $\mathrm{GLU}(\mathrm{mmol} / \mathrm{L})$ & $6.0 \pm 1.5$ & $5.8 \pm 1.2$ & $5.1 \pm 0.5$ & 11.4 & $<0.001$ \\
\hline $\mathrm{ALB}(\mathrm{g} / \mathrm{L})$ & $43.9 \pm 3.5$ & $45.2 \pm 2.6$ & $44.6 \pm 2.0$ & 4.3 & 0.017 \\
\hline
\end{tabular}

Abbreviations: AG, acute gout; IG, intercritical gout; HC, healthy controls; WBC, white blood cell; GR, granulocyte; ESR, erythrocyte sedimentation rate; UA, uric acid; GLOB, Globulin; TG, total triglycerides; TC, total cholesterol; HDLC, high density lipoprotein cholesterol; LDLC, low density lipoprotein cholesterol; VLDL, very lowdensity lipoprotein; apoAI, Apolipoprotein AI; apoBI00, Apolipoprotein BI00; GLU, glucose; ALB, albumin. 


\section{Animals}

MiR-223 KO mice were produced refer to the described method $^{15}$ and kindly provided by the CBR Institute for Biomedical Research, Harvard Medical School, Boston, USA. WT C57BL/6 mice were purchased from the Jackson Laboratory, Bar Harbor, USA. All mice used in these experiments were $8-10$ weeks old. All handling of the mice and experimental procedures were developed in accordance with the requirements of the Institutional Animal Care and Use Committee of Henry Ford Health System (Detroit, USA) and also were approved by the Committee.

\section{MSU Crystals Formation}

MSU crystals were prepared as described previously. ${ }^{16}$ Briefly, $1.0 \mathrm{~g}$ uric acid (Sigma-Aldrich, USA) was dissolved in $200 \mathrm{~mL}$ sterile water containing $6.0 \mathrm{~mL}$ of 1 $\mathrm{M} \mathrm{NaOH}$. The $\mathrm{pH}$ was adjusted to 7.2 and the solution was sterilized by heating at $180^{\circ} \mathrm{C}$ for $2 \mathrm{~h}$. The precipitate was filtered from the solution, dried under low heat and suspended in phosphate-buffered saline (PBS) at a concentration of $50 \mathrm{mg} / \mathrm{mL}$. All reagents were prepared under pyrogen-free conditions.

\section{BMDMs Culture and MSU Stimulation}

BMDMs were cultured in RPMI-1640 (Gibco, Life Technologies, USA) supplemented with $10 \%$ fetal bovine serum (FBS), penicillin (100 units/mL), streptomycin $(100 \mu \mathrm{g} / \mathrm{mL})$ and $30 \mathrm{ng} / \mathrm{mL}$ macrophage colony-stimulating factor (\#0914245, Peprotech, USA). After 7 days, the cells were harvested with $0.25 \%$ trypsin. The phenotypic validation of BMDMs (Figure 1B) was measured by flow cytometry and staining with FITC-conjugated anti-CD11b and PE-conjugated anti-F4/80 antibodies (both diluted 1:200). The BMDMs were double-positive for CD11b and F4/80. The BMDMs were harvested at 30 or 60 minutes after MSU crystal challenge for MSU phagocytosis of macrophages. Phagocytosis of MSU crystals was analyzed by the side scatter (SSC) change in flow cytometry.

The harvested BMDMs were divided into $2 \times 10^{6}$ cells/ well in a 6 well/plate containing $1 \mathrm{~mL}$ RPMI-1640+10\% FBS. According to the experimental protocol for the in vitro experiment, ${ }^{17}$ the BMDMs were primed with $50 \mathrm{ng} / \mathrm{mL}$ lipopolysaccharide (LPS) for 4 hours before the BMDMs were stimulated with MSU crystals suspension (MSU $100 \mu \mathrm{g} / \mathrm{mL}$ final concentration) for 4 or $8 \mathrm{~h}$. The cells were harvested for measurement of miRNA, mRNA or protein. In addition, intracellular tumor necrosis factor (TNF)- $\alpha$ production in
BMDMs treated with MSU for 2 or $4 \mathrm{~h}$ was measured by a FACSAria II (BD Biosciences, USA).

\section{Gout Model}

Mice were placed under anesthesia [150:10 mg/kg ketamine:xylazine injected intraperitoneally] and were injected with the MSU crystal suspension into the right foot pad (1 mg suspended in $40 \mu \mathrm{L}$ PBS) or ankle joint $(0.5 \mathrm{mg}$ suspended in $20 \mu \mathrm{L}$ PBS). ${ }^{18}$ Inflammation parameters were evaluated with an electronic caliper post-MSU crystal injection at different time points (6, 24 and $48 \mathrm{~h})$.

An injection of $5 \mathrm{~mL}$ sterile air into the subcutaneous tissue on the back of each mouse was carried out to form an air pouch. On day 7, the MSU crystal suspension (3 mg) was injected into the air pouch. ${ }^{19}$ In the MSUinduced peritonitis model, MSU crystals (3 $\mathrm{mg}$ ) were injected into the peritoneal cavity. ${ }^{20}$ The total number of cells in air pouch lavage fluid (APLF) and peritoneal cavity lavage fluid (PCLF) containing $2 \mathrm{~mL}$ PBS were harvested at different time points and counted using a hematocytometer.

\section{Flow Cytometry Analysis}

The BMDMs $\left(2 \times 10^{6}\right)$ treated with MSU for 2 or $4 \mathrm{~h}$ were harvested and stained with monoclonal antibody $(\mathrm{mAb})$ F4/80-PE or CD11b-FITC for $30 \mathrm{~min}$ at $4{ }^{\circ} \mathrm{C}$. The cells were then fixed by intracellular fixation buffer for $30 \mathrm{~min}$ at $4^{\circ} \mathrm{C}$. After rinsing twice with permeabilization buffer, the cells were dyed with mAb TNF- $\alpha-\mathrm{PE}-\mathrm{Cy} 7$ for $30 \mathrm{~min}$ at $4{ }^{\circ} \mathrm{C}$.

APLF or PCLF cells $\left(2 \times 10^{6}\right)$ were incubated with Fc block (clone 2.4G2) for $15 \mathrm{~min}$ and then stained with $\mathrm{mAb}$ Ly-6G-PE, F4/80-APC, and CD11b-FITC for $30 \mathrm{~min}$ at $4^{\circ}$ C. The cells were suspended in running buffer (PBS containing $0.5 \% \mathrm{FBS}$ and $2 \mathrm{mM}$ EDTA), and then sorted and analyzed on a FACSAria II (BD Biosciences). All antibodies were purchased from eBioscience (USA). Data were acquired using CellQuest software (BD Biosciences) and analyzed by FlowJo software (Tree Star Inc.).

\section{RNA Isolation, cDNA Synthesis and Quantitative PCR (qPCR)}

Peripheral blood mononuclear cells (PBMCs) from patients with gout and $\mathrm{HC}$ were isolated using FicollHypaque density gradient centrifugation. Total RNA in human PBMCs and mouse BMDMs was extracted using Trizol reagent (Invitrogen, USA) and reverse-transcribed 
A
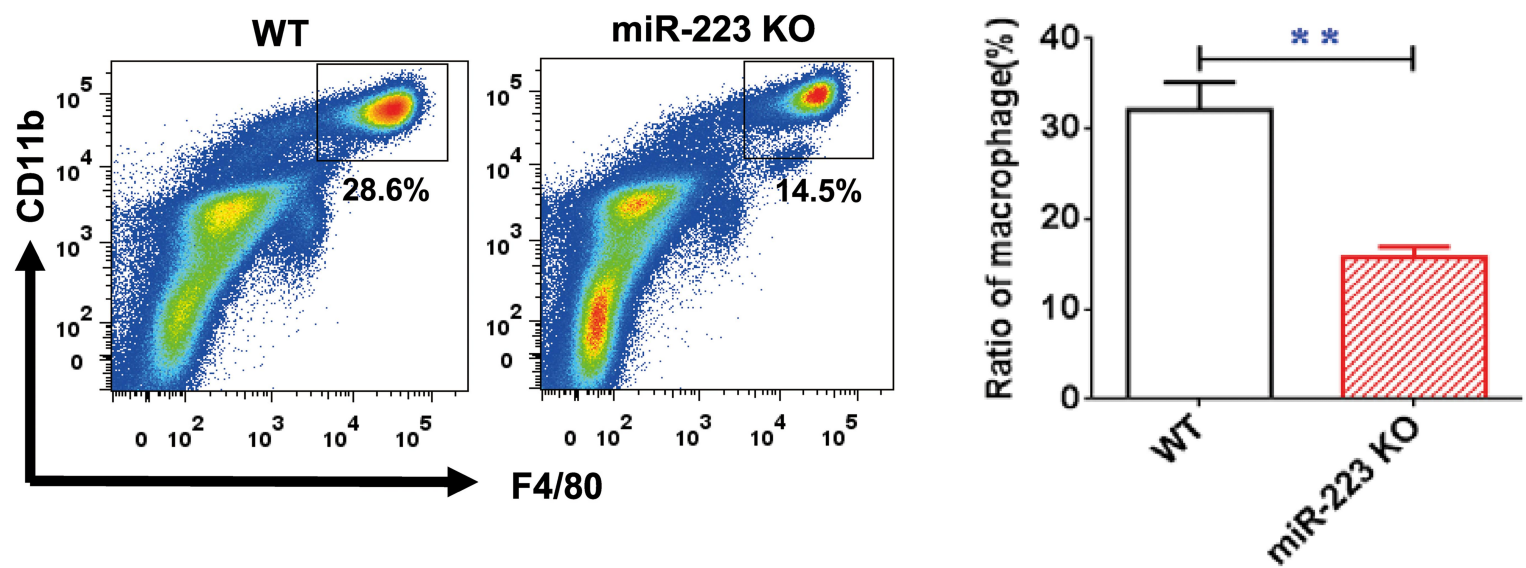

B
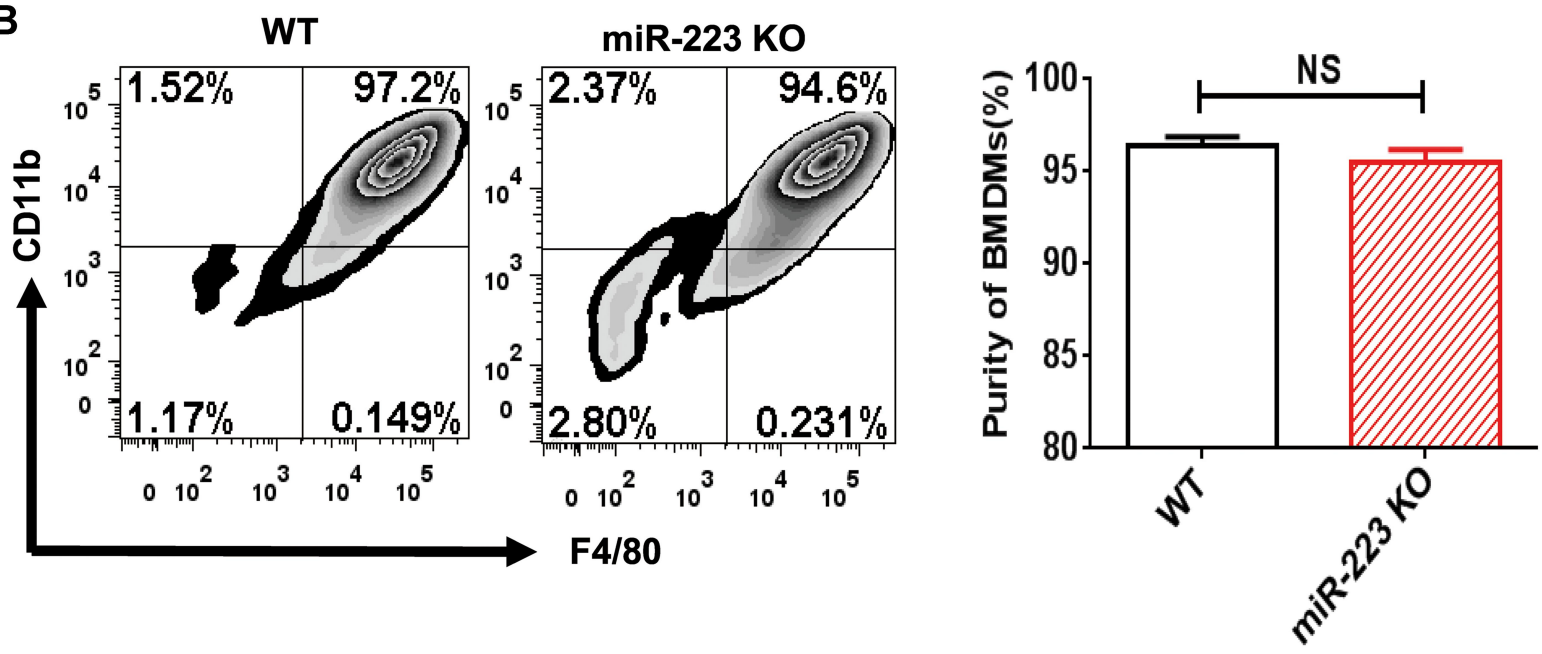

C
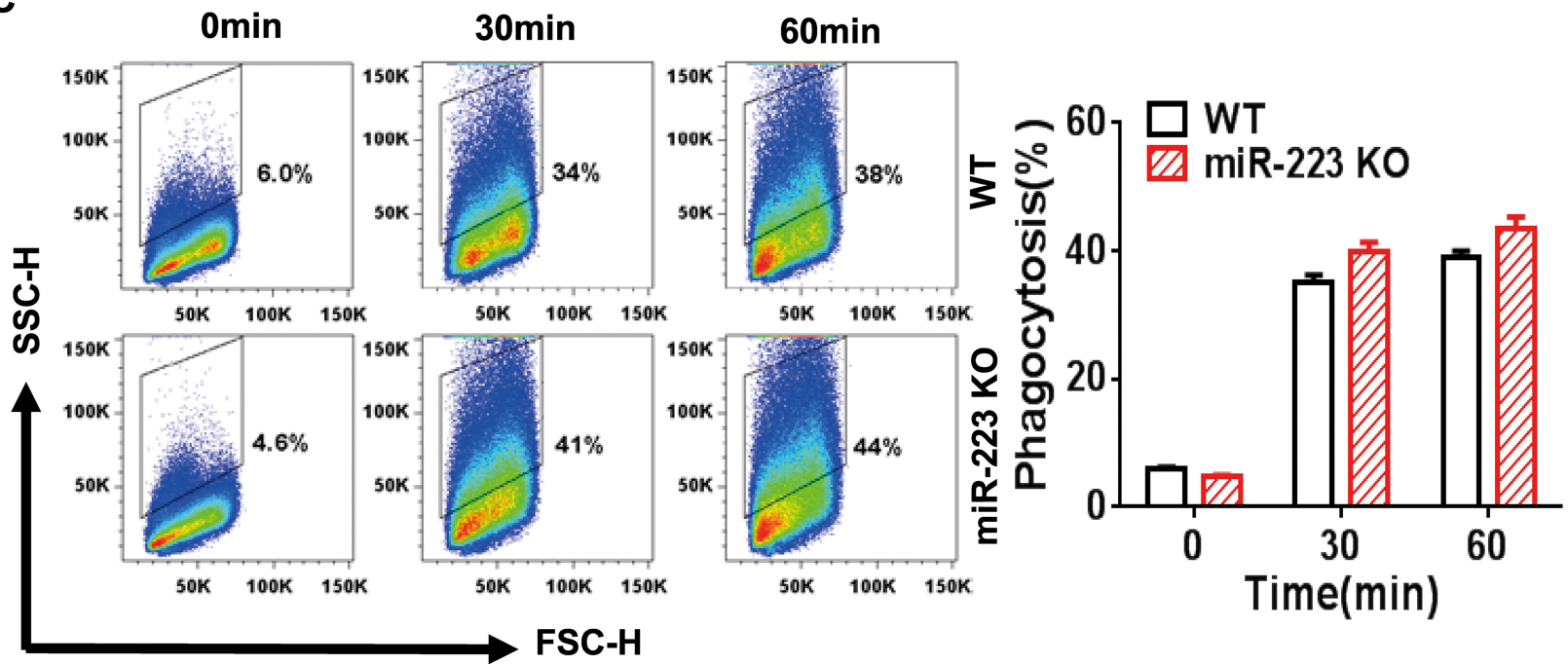

Figure I miR-223 was required for macrophage homeostasis, but not development and phagocytosis. (A) The cells harvested from peritoneal cavity with $2 \mathrm{~mL}$ PBS were stained with anti-F4/80 and anti-CDI I b antibodies and analyzed by flow cytometry. (B) The bone marrow cells were cultured and induced by Dulbecco's modified Eagle's medium (DMEM) with 30 $\mathrm{ng} / \mathrm{mL}$ macrophage colony-stimulating factor for 7 days. The DMEM was refreshed every 2 days until the cells were harvested and the purity of the bone marrow-derived macrophages (BMDMs) were then identified with flow cytometry. The BMDMs were represented by positive F4/80 and CDI Ib. (C) Monosodium urate (MSU) crystal phagocytosis was analyzed by flow cytometry in BMDMs from miR-223 KO and WT mice at different time points after MSU crystal challenge in vitro. $n=3-5$ for each group and unpaired $t$-test was used for each group at indicated time points. The results are representative of 3 independent experiments. $n=3-5$ for each group. $* * p<0.01$.

Abbreviation: NS, not significant. 
into cDNA using reverse transcription reagents (Invitrogen, USA) according to the manufacturer's protocols. Real-time qPCR was performed with Power SYBR Green PCR Master Mix (Applied Biosystems, USA). The gene primer sequences (Table 2) were synthesized by
Eurofins Genomics (Louisville, USA) or a biological engineering company (Shanghai, China). Gene expression analysis was performed using the $2^{-\Delta \Delta \mathrm{CT}}$ or $2^{-\Delta \mathrm{CT}}$ method. The expression of miR-223 (ABI: ID002295, miR-223$3 \mathrm{p}$ ) in PBMCs, sorted cells and BMDMs were measured

Table 2 Sequences of Human and Murine Genes Primers Used in Our Study

\begin{tabular}{|c|c|c|}
\hline Gene Name & & Primer Sequence \\
\hline \multirow[t]{2}{*}{ Human NLRP3 } & Forward & 5'-CCCCGTGAGTCCCATTA-3' \\
\hline & Reverse & 5'-GACGCCCAGTCCAACAT-3' \\
\hline \multirow[t]{2}{*}{ Human $\beta$-actin } & Forward & 5'-GAGCTACGAGCTGCCTGACG -3' \\
\hline & Reverse & 5'-GTAGTTTCGTGGATGCCACAG-3' \\
\hline \multirow[t]{2}{*}{ Murine NLRP3 } & Forward & 5'-CGTGGTTTCCTCCTTTTGTATT-3' \\
\hline & Reverse & 5'-CGACCTCCTCTCСTCTCTTCTT-3' \\
\hline \multirow[t]{2}{*}{ Murine IL-I $\beta$} & Forward & 5'-GGGCCTCAAAGGAAAGAATC-3' \\
\hline & Reverse & 5'-CTCTGCTTGTGAGGTGCTGA-3' \\
\hline \multirow[t]{2}{*}{ Murine TNF- $\alpha$} & Forward & 5'-ACAAAGGTGCCGCTAACCACATGT-3' \\
\hline & Reverse & 5'-ATGCTGCTGTTTCAGTCGAAGGCA-3' \\
\hline \multirow[t]{2}{*}{ Murine $\beta$-actin } & Forward & 5'-CAACGAGCGGTTCCGATG-3' \\
\hline & Reverse & 5'-GCCACAGGATTCCATACCCA-3' \\
\hline \multirow[t]{2}{*}{ Murine ASC } & Forward & 5'-TCACAGAAGTGGACGGAGTG-3' \\
\hline & Reverse & 5'-TGTCTTGGCTGGTGGTCTCT-3' \\
\hline \multirow[t]{2}{*}{ Murine caspase-I } & Forward & 5'-CGTGGAGAGAAACAAGGAGTG-3' \\
\hline & Reverse & 5'-AATGAAAAGTGAGCCCCTGAC-3' \\
\hline \multirow[t]{2}{*}{ Murine $\mathrm{P}_{2} \mathrm{X}_{7} \mathrm{R}$} & Forward & 5'-ATCCACTTCCCCGGCCACAA-3' \\
\hline & Reverse & 5'-CCTCCAGTGCCGAAAACCAGG-3' \\
\hline \multirow[t]{2}{*}{ Murine TLR2 } & Forward & 5'-CCAAAGAGCTCGTAGCATCC-3' \\
\hline & Reverse & 5'-AGGGGCTTCACTTCTCTGCT-3' \\
\hline \multirow[t]{2}{*}{ Murine TLR4 } & Forward & 5'-CAAGAACATAGATCTGAGCTTCAACCC-3' \\
\hline & Reverse & 5'-GCTGTCCAATAGGGAAGCTTTCTAGAG-3' \\
\hline \multirow[t]{2}{*}{ Murine MyD88 } & Forward & 5'-CGGAACTTTTTCGATGCCTTT-3' \\
\hline & Reverse & 5'-TAGTTGCCGGATCATCTCCT-3' \\
\hline \multirow[t]{2}{*}{ Murine STATI } & Forward & 5'-TCACAGTGGTTCGAGCTTCAG-3' \\
\hline & Reverse & 5'-CGAGACATCATAGGCAGCGTG-3' \\
\hline \multirow[t]{2}{*}{ Murine STAT3 } & Forward & 5'-GGGCCATCCTAAGCACAAAG-3' \\
\hline & Reverse & 5'-GGTCTTGCCACTGATGTCCTT-3' \\
\hline \multirow[t]{2}{*}{ Murine SOCSI } & Forward & 5'-CACCTTCTTGGTGCGCG-3' \\
\hline & Reverse & 5'-AAGCCATCTTCACGCTGAGC-3' \\
\hline \multirow[t]{2}{*}{ Murine IL-6 } & Forward & 5'-TCCAGTTGCCTTCTTGGGAC-3' \\
\hline & Reverse & 5'-GTACTCCAGAAGACCAGAGG-3' \\
\hline \multirow[t]{2}{*}{ Murine MCP-I } & Forward & 5'-CATCCACGTGTTGGCTCA-3' \\
\hline & Reverse & 5'-GATCATCTTGCTGGTGAATGAGT-3' \\
\hline \multirow[t]{2}{*}{ Murine $\mathrm{CXCL5}$} & Forward & 5'-ATCACCTCCAAATTAGCGATCA-3' \\
\hline & Reverse & 5'-TTCTGTTGCTGTTCACGCT-3' \\
\hline
\end{tabular}


using TaqMan MicroRNA Assays (Applied Biosystems, USA) according to the manufacturer's protocols. The TaqMan MicroRNA Assay for U6 snRNA (ABI: ID001973) was used to normalize the relative abundance of microRNAs.

\section{Enzyme-Linked Immunosorbent Assay (ELISA) Analysis}

IL-1 $\beta$ (88-7013-88), IL-6 (88-7064-88), and MCP-1

(88-7503-88) in APLF or PCLF were determined using ELISA kits from eBioscience (USA) following the manufacturer's instructions. The 96-well microplates were read by a VICTOR X3 multilabel plate reader.

\section{Western Blot Analysis}

Proteins in BMDMs or PBMCs were extracted by RIPA lysis buffer (Thermo Scientific) containing protease or phosphatase inhibitors. The proteins $(50-70 \mu \mathrm{g})$ were separated by $10 \%$ SDS-PAGE and transferred to a polyvinylidene fluoride membrane (Bio-Rad). After blocking with $5 \%$ non-fat milk (Sigma, USA) for $1 \mathrm{~h}$, the membrane was incubated with primary antibodies [anti-NLRP3 antibody $(\# 15,101)$, anti-IL-1 $\beta$ antibody (\#4283), and anti- $\beta$-actin antibody (\#3700) (all from Cell Signaling Technology)] at $4{ }^{\circ} \mathrm{C}$ overnight. Secondary antibodies conjugated to horseradish peroxidase were incubated for $1 \mathrm{~h}$ at room temperature. Immunoreactive proteins were visualized using an enhanced chemiluminescence system (Amersham Biosciences), according to the manufacturer's instructions. Fold changes were assessed using Image $\mathbf{J}$ software.

\section{Statistical Analysis}

Data were analyzed with Prism 6.0 (GraphPad software). Data are expressed as mean \pm standard deviation. Differences between experimental groups were tested using the unpaired $t$-test or a one-way analysis of variance (ANOVA). A p values $<0.05$ was considered statistically significant.

\section{Results}

\section{MSU Crystals Changed miR-223 Expression in BMDMs from WT Mice}

We firstly validated the expression of miR-223 in BMDMs and large peritoneal macrophages (LPMs). As shown in Figure 2A, the levels of miR-223 in BMDMs and LPMs from miR-223 KO mice were significantly lower than those from WT mice. In the in vitro functional experiment, miR-223 was quickly and strongly up-regulated in BMDMs from WT mice after MSU treatment in vitro and then decreased rapidly to an extremely low level. However, the baseline level was maintained in miR-223 $\mathrm{KO}$ mice (Figure 2B). These data indicated that miR-223 could be significantly inhibited by MSU crystals although it was promoted at early phase.

\section{A}

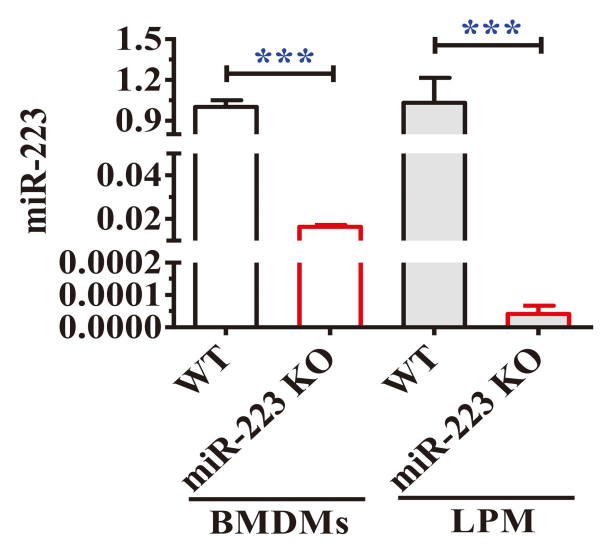

B

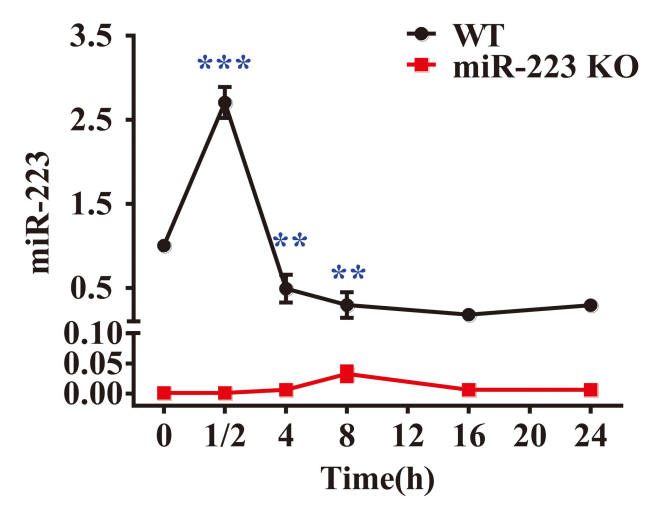

Figure 2 miR-223 was validated both in miR-223 knock-out (KO) and wild-type (WT) mice and changed in bone marrow-derived macrophages (BMDMs) from WT mice treated with monosodium urate (MSU) crystals in vitro. (A) Relative expression of miR-223 was measured by TaqMan-PCR in BMDMs and in large peritoneal macrophages (LPMs) from WT and miR-223 KO mice. (B) Relative expression of miR-223 was measured by TaqMan-PCR in BMDMs from WT mice treated with MSU crystals (I00 $\mu g /$ $\mathrm{mL}$ ) for different time-points up to $24 \mathrm{~h}$. Point 0 represented treatment without MSU crystals. The results are representative of 3 independent experiments. $\mathrm{n}=3-5$ for each group, and the unpaired $t$-test was used for each group, and the Bonferroni post-test was used for the comparison between baseline and MSU crystals. Compared to the untreated group. $* * P<0.01, * * * p<0.001$. 


\section{miR-223 Was Required for Macrophage Homeostasis, but Not Development and Phagocytosis}

We examined whether miR-223 deficiency could impair macrophage development and homeostasis using miR-223 KO mice. In comparison with WT mice, the percentage of macrophages was significantly down-regulated in cells profile from the peritoneal cavity of miR-223 KO mice (Figure 1A). The percentage of BMDMs in miR-223 KO mice was not significantly changed compared to WT mice (Figure 1B). It suggested that miR-223 may be required for macrophage homeostasis, but not macrophage development. To further evaluate the potential role of miR-223 in the MSU crystals phagocytosis of macrophages, BMDMs were incubated with MSU crystals. The phagocytosis of macrophages from miR-223 $\mathrm{KO}$ mice was comparable to that from WT mice (Figure 1C), suggesting that lack of miR-223 did not block the macrophage phagocytosis.

\section{miR-223 Deficiency Exacerbated}

\section{MSU-Induced Inflammation in the Foot Pad and Ankle Joint Models}

To further address whether miR-223 deficiency affects the phenotype in the MSU-induced gouty inflammatory response in vivo, foot pad and ankle joint models were applied to mimic acute gouty arthritis in humans. Compared with WT mice, significant increases in swelling indices of the foot pad were observed in miR-223 KO mice at $6 \mathrm{~h}$ and peaked at $24 \mathrm{~h}$, and were still high at $48 \mathrm{~h}$ after administration of MSU crystals although this almost returned to the same level seen at 6 h (Figure 3A). Consistent with the findings with the foot pad, the ankle swelling indices in miR-223 KO mice also markedly increased compared with those in WT mice (Figure 3B). In addition, inflammatory cells were assayed by immunohistochemistry of ankle joint tissue slices. Inflammatory cell infiltration was significantly increased in miR-223 KO mice compared with WT mice (Figure 3C). These data collectively demonstrated that miR-223 deficiency could prominently promote the clinical phenotype of MSUinduced inflammatory response.

\section{miR-223 Deficiency Aggravated MSU-Induced Inflammatory Cell Infiltration and Cytokine Release in the}

\section{Air Pouch and Peritonitis Models}

To ascertain the effects of miR-223 deficiency in MSUinduced inflammation in vivo, a murine air pouch model of MSU crystals-induced inflammation was assessed at different time-points. At $12 \mathrm{~h}$ after MSU injection, there was a marked increase in the total cell number in subcutaneous APLF (Figure 4A), and the total cell number in APLF in miR-223 $\mathrm{KO}$ mice was maintained at a high level at $24 \mathrm{~h}$. Moreover, for neutrophils (Figure 4B), as the major APLF population, both the cell number and the ratio increased at 12 and $24 \mathrm{~h}$ in miR$223 \mathrm{KO}$ mice (Figure 4C and D). However, both the cell
A
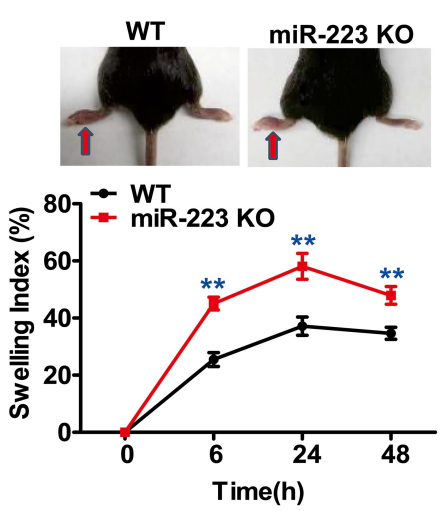

B
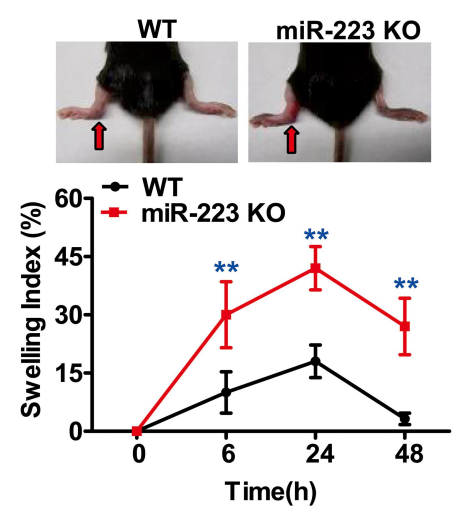

C

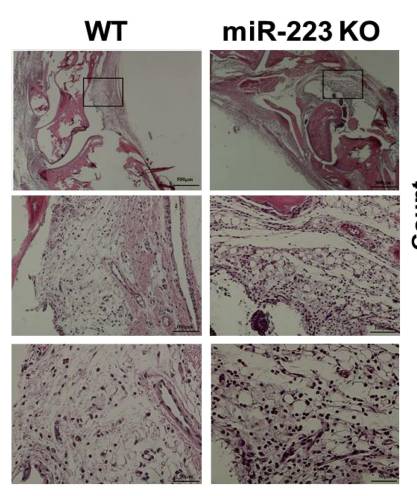

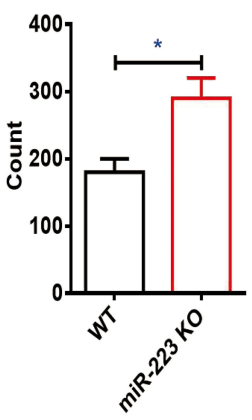

Figure 3 miR-223 deficiency exacerbated acute arthritis in response to monosodium urate (MSU) crystals. (A) I mg/40 $\mu \mathrm{L}$ MSU suspension was injected into the right foot pad of wild-type (WT) and miR-223 knock-out (KO) mice, and thickness of the foot pad was determined at $0,6,24$ and $48 \mathrm{~h}$ after MSU administration. (B) $0.5 \mathrm{mg} / 20 \mu \mathrm{L}$ MSU crystals were injected into the left ankle joints, and the ankles were measured at 0, 6, 24 and $48 \mathrm{~h}$ after MSU administration; swelling was expressed as a ratio $>0.15$ which indicated inflammation. (C) The ankle joints were harvested $12 \mathrm{~h}$ after MSU treatment in $4 \%$ formalin and then tissue slices were prepared and stained with hematoxylin and eosin $(\mathrm{H} \& E)$. Data are expressed as mean \pm SEM. The results are representative of 3 independent experiments. $n=6-8$ for each group and the unpaired $t$-test was used for each group at the indicated time points. $* P<0.05, * * p<0.01$. 
A

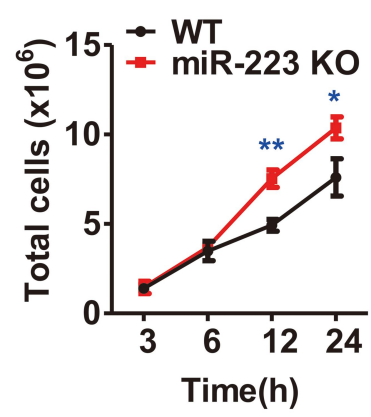

C

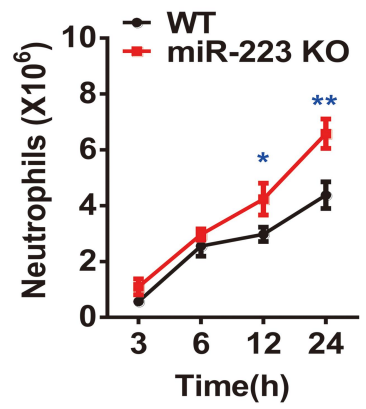

B

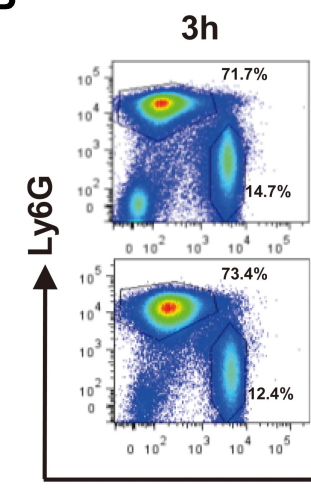

$6 \mathrm{~h}$

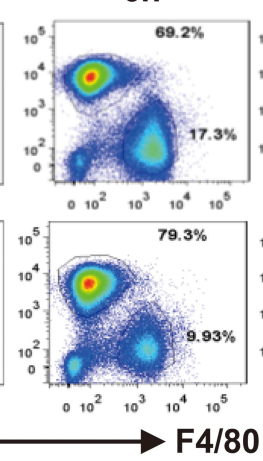

E

D

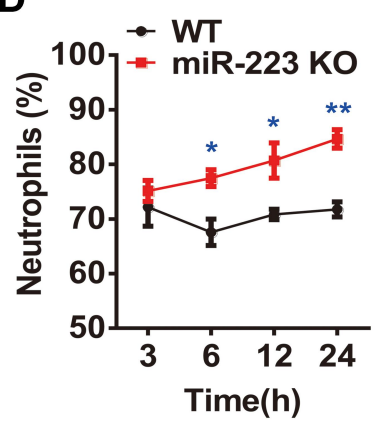

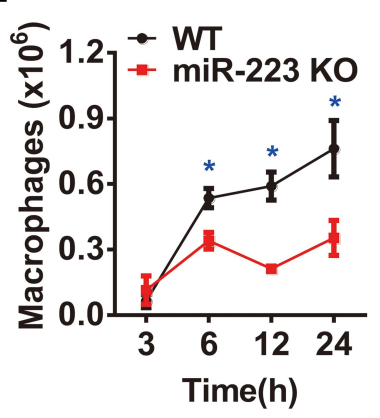

$12 \mathrm{~h}$

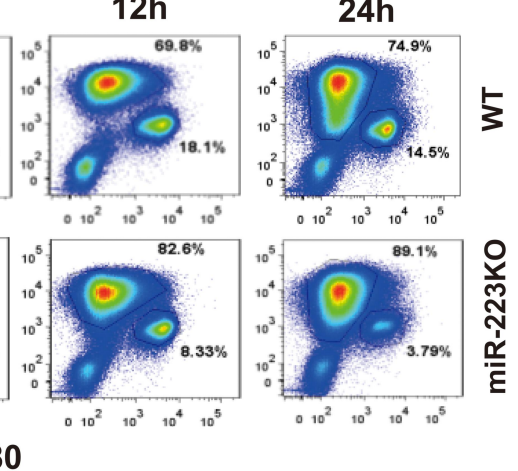

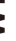

F
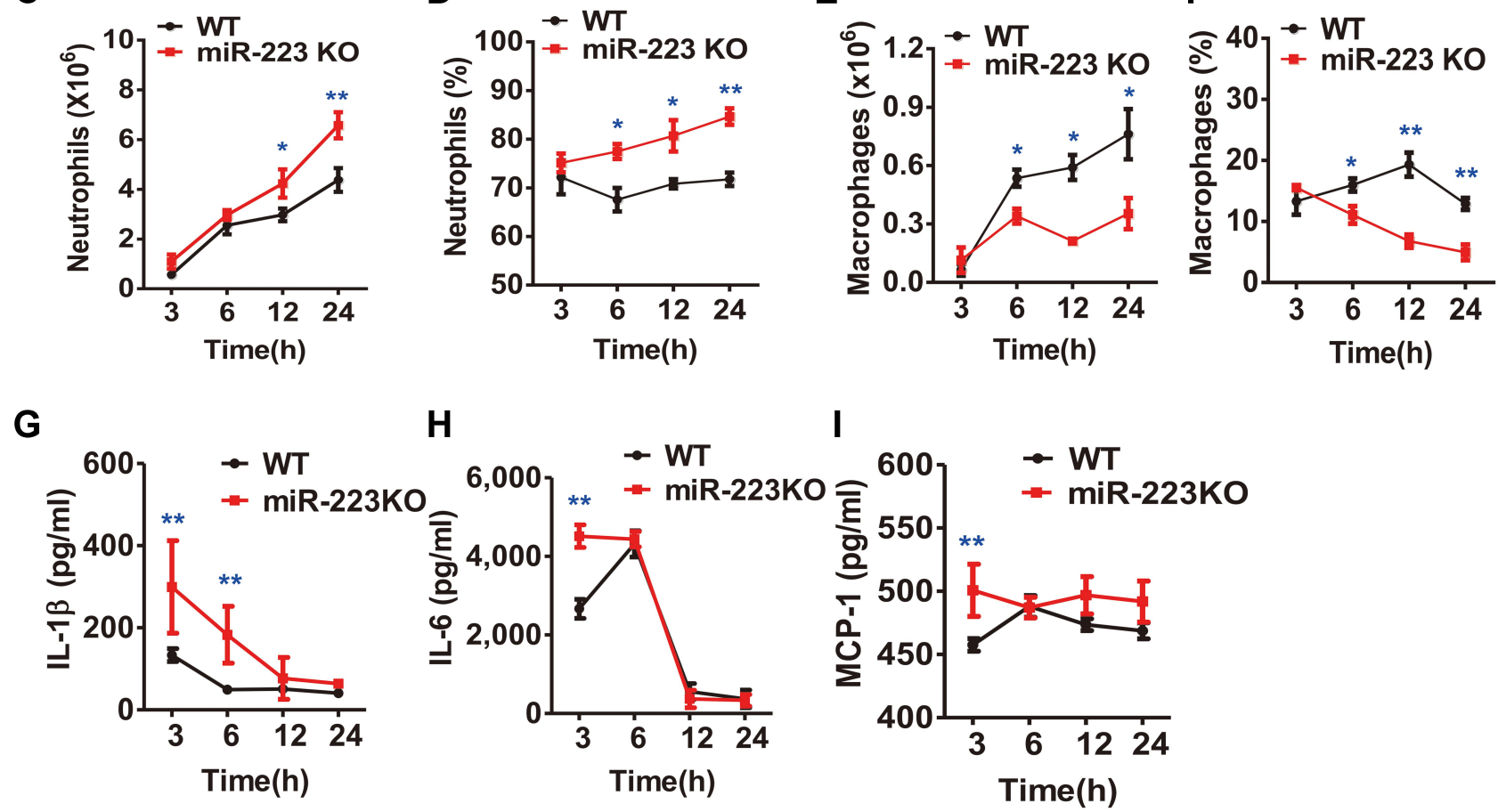

H

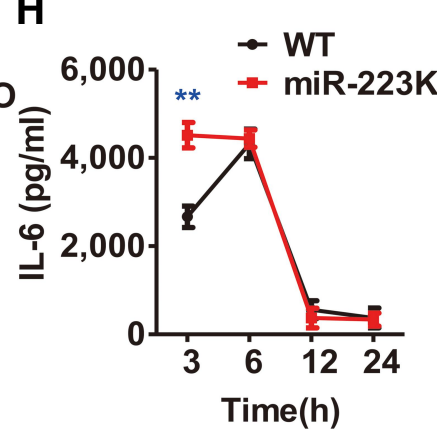

I

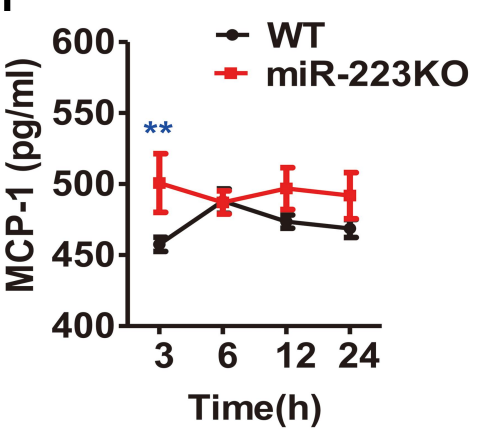

Figure 4 miR-223 deficiency enhanced monosodium urate (MSU)-induced inflammatory cell infiltration and cytokine secretion in the air pouch model. (A) Total cell numbers were counted using a hematocytometer. (B) Neutrophils and macrophages were gated by Fluorescence-Activated Cell Sorting (FACS). (C-F) Infiltrated neutrophils (C, D) and macrophages $(\mathbf{E}, \mathbf{F})$ were analyzed using Flowjo software. Infiltrated macrophages were represented by $\mathrm{F} 4 / 80^{+}$, while neutrophils were represented by Ly6G ${ }^{+}$. (G-I) The protein levels of IL-I $\beta(\mathbf{G})$, IL-6 (H) and MCP-I (I) in air pouch lavage fluid harvested at 3, 6, I2 and $24 \mathrm{~h}$ were measured using ELISA. $\mathrm{n}=4-6$ for each group and the unpaired $t$-test was used for each group at the indicated time points. $* P<0.05, * * P<0.01$.

number and the ratio of macrophages, the second major infiltrating cells, decreased at 6, 12 and $24 \mathrm{~h}$ (Figure 4E and F). Furthermore, the levels of IL-1 $\beta$, IL-6 and MCP-1 in APLF, particularly at the early phase of the inflammatory response, were markedly elevated in miR-223 KO mice compared with WT mice (Figure 4G-I).

The peritoneal cavity model was used to analyze the cellular phenotype of miR-223 in gout. In comparison with WT mice, it was found that the total cell number in PCLF in miR-223 KO mice increased at 3 and 6 $\mathrm{h}$ (Figure 5A). Of note, infiltrating neutrophils
(Figure 5B) were not only increased in number but also in ratio in miR-223 $\mathrm{KO}$ mice after MSU treatment at 3 and $6 \mathrm{~h}$ (Figure $5 \mathrm{C}$ and $\mathrm{D}$ ). However, neither the number nor the ratio of macrophages were significantly different (Figure 5E and F). Moreover, there was a significant elevation of IL-1 $\beta$, IL-6 and MCP-1 in PCFL from miR-223 KO mice (Figure 5G-I). Our results suggested that deficiency of miR-223 could aggravate infiltration of neutrophils and production of pro-inflammatory cytokines implicated in the process of gouty inflammation. 

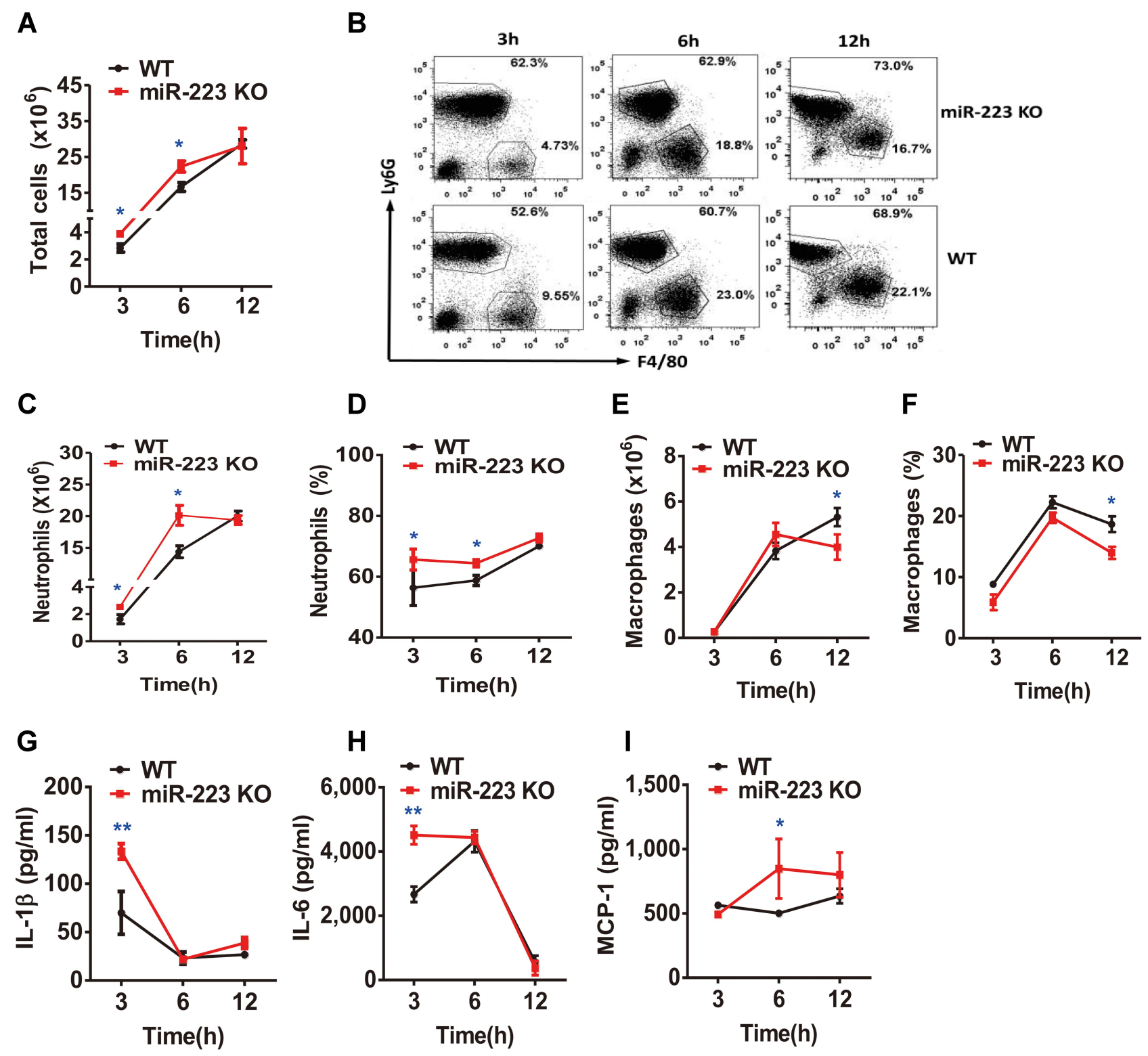

Figure 5 miR-223 deficiency aggravated neutrophil infiltration and pro-inflammatory cytokine secretion in monosodium urate (MSU)-induced peritonitis. (A) 3 mg/0.5 mL MSU suspension was injected into the peritoneal cavity, the lavage fluid was harvested at different time points. (A) Total cell numbers were counted using a hematocytometer. (B-F) Neutrophils and macrophages were analyzed by FACS. Macrophages were represented by F4/80+, while neutrophils were represented by Ly6G+. (G-I) IL-I $\beta$, IL-6 and MCP-I levels in peritoneal cavity lavage fluid at the indicated time points were detected using ELISA. The results are representative of 3 independent experiments. $n=4-6$ for each group and the unpaired $t$-test was used for each group at the indicated time points. $* P<0.05$, $* * P<0.01$.

\section{miR-223 Deficiency Enhanced the MSU-Induced Inflammatory Response by Directly Targeting NLRP3}

To further clarify the potential molecular mechanism of miR223 in the enhancement of MSU-induced gouty inflammation, pro-inflammatory gene expression was evaluated in BMDMs exposed to MSU in vitro. In comparison with WT mice, TNF$\alpha$ mRNA level was significantly increased in miR-223 KO BMDMs exposed to MSU crystals (Figure 6A). It was further confirmed that the level of TNF- $\alpha$ secretion was markedly elevated in miR-223 KO BMDMs treated with MSU for 2 and $4 \mathrm{~h}$ (Figure 6B and C). In addition, the key genes related to the signaling pathways in gouty inflammation were not altered in miR-223 KO mice (Supplementary Figure 1 and 2).

The mRNA and protein levels of NLRP3, which was one of the miR-223 potential target genes in both humans and mice, were measured in BMDMs treated with MSU in vitro. As expected, NLRP3 mRNA levels were not altered in miR-223 
A

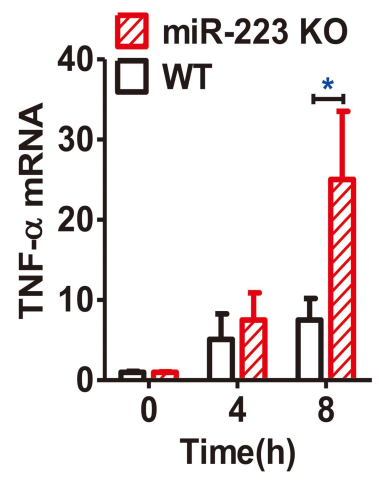

D

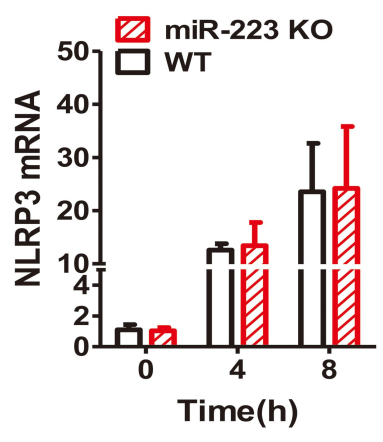

B

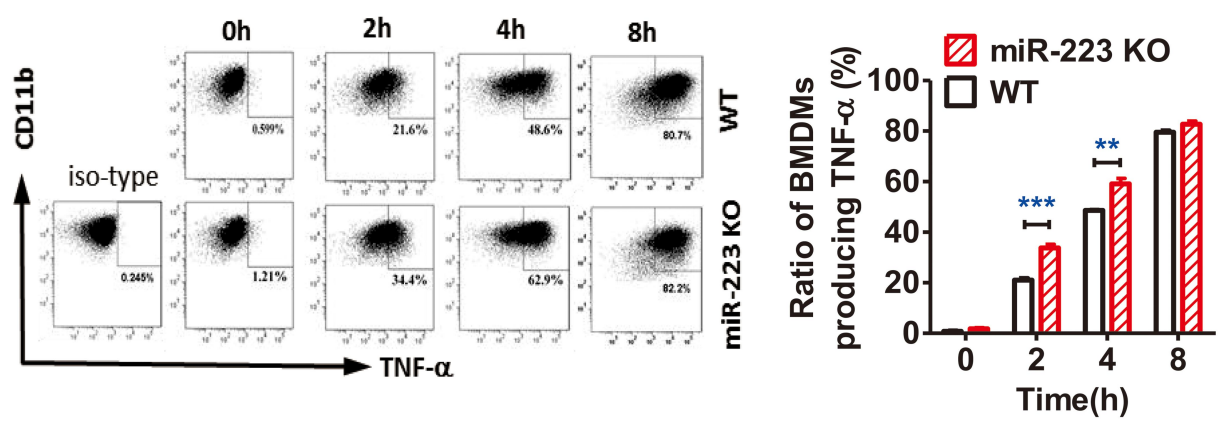

C
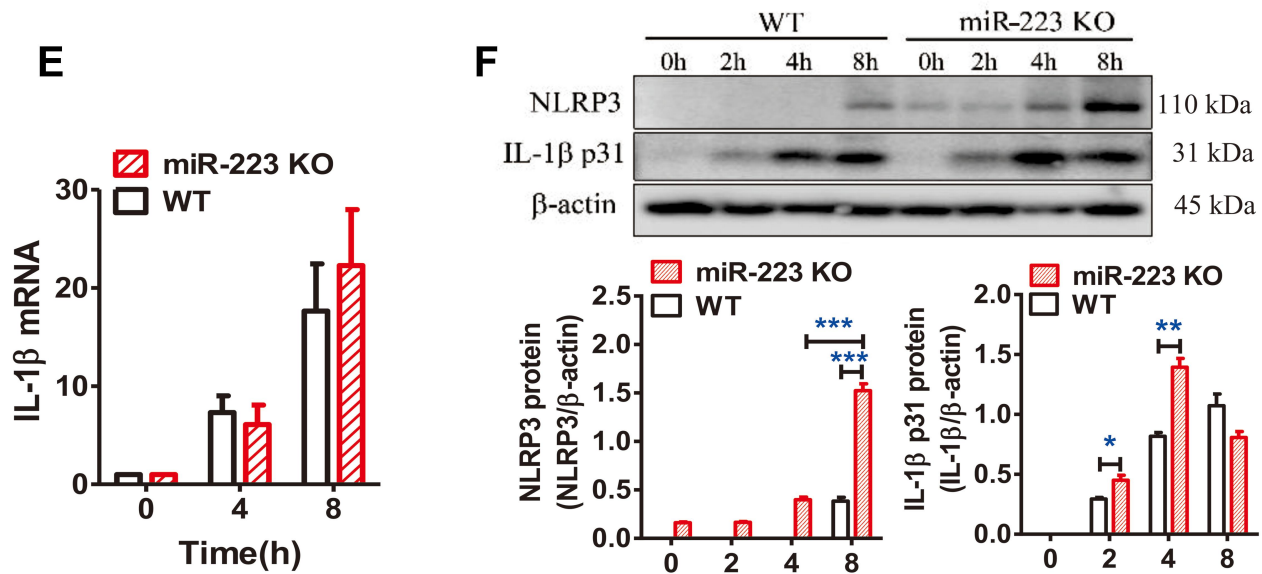
A

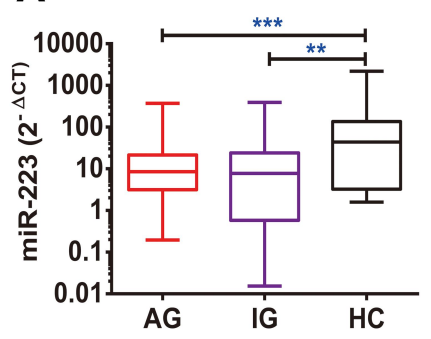

C

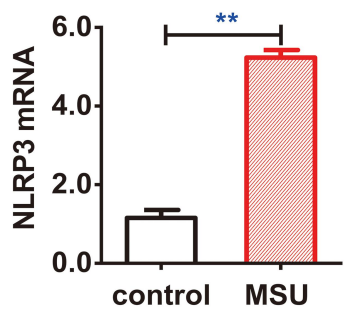

B

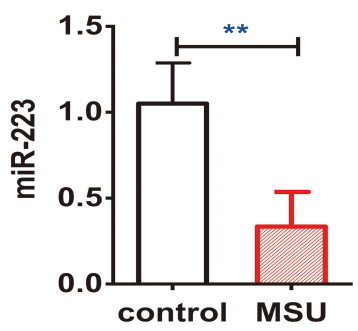

D

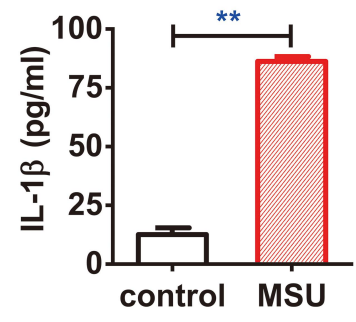

Figure 7 miR-223 level was down-regulated in peripheral blood mononuclear cells (PBMCs) from patients with gout. (A) miR-223 level was measured in PBMCs from patients with acute gout $(A G, n=80)$, intercritical gout $(I G, n=40)$ and healthy controls $(\mathrm{HC}, \mathrm{n}=40)$. (B-D) The PBMCs from HC treated with MSU crystals $(100 \mu \mathrm{g} / \mathrm{mL})$ for $12 \mathrm{~h}$ in vitro were harvested for measurement of miR-223 (B), NLRP3 mRNA (C) and IL-I $\beta$ protein (D) in the supernatant. The miRNA or mRNA level was detected by real-time $q P C R$, and the protein level was measured using ELISA. The results are representative of 3 independent experiments. $n=3$ for each group (B-D). One-way analysis of variance or the paired $t$-test, and the Bonferroni post-test were used for comparisons between the groups. $* * P<0.01$. $* * * P<0.00 \mathrm{I}$.

\section{Discussion}

Although MSU has been identified as a causative agent in gout for more than 100 years, its complicated mechanism was unknown until the discovery of the NLRP3 inflammasome a decade ago. ${ }^{21}$ Currently, the NLRP3 inflammasome is considered a master switch that modulates gouty inflammatory response. Emerging data have demonstrated that miRNAs negatively regulated gene expression posttranscriptionally by binding to the $3^{\prime}$-UTR of target mRNAs. ${ }^{7,8}$ Previous in vitro studies reported that miR223 played a crucial role in modulation of MSU-induced inflammatory response due to negative regulation of NLRP3 inflammasome activity. ${ }^{11,22}$ However, there is still a lack of direct evidence to further support that miR223 is indeed involved in the MSU-induced inflammation.

To better understand the biological function of miR223 involved in gouty inflammation in vitro and in vivo, we confirmed that miR-223 expression was up-regulated in the early phase and then decreased in BMDMs from WT mice after MSU treatment in vitro, but this did not occur in miR-223 KO mice. These results indicated that miR-223 expression was promoted in the early phase of
MSU-induced acute gouty inflammation and was suppressed following constant challenge with MSU crystals. However, the exact mechanisms of those change still remained unclear. It could be attribute to the timeliness of miR-223 expression and the several fine-regulatory mechanisms such as regulation of transcript factor, ${ }^{23}$ circRNA sponge ${ }^{24}$ and macrophage polarization. ${ }^{10}$

MiR-223 is involved in determining the identity of cell types in the myeloid compartment, especially the neutrophils and macrophages. ${ }^{10}$ A previous study ${ }^{25}$ showed that murine peritoneal cavity harbors a number of immune cells, which is approximately composed of $30 \%$ in macrophages, $50 \%$ in B cells and $10 \%$ in $\mathrm{T}$ cells. It has been shown that lack of miR-223 could affect proliferation and differentiation of neutrophils. ${ }^{15}$ Macrophage, as one of the myeloid cells, plays a critical role in recognition and phagocytosis of MSU crystals and then triggers NLRP3 inflammasome activation, leading to IL- $1 \beta$ release. ${ }^{26-28}$ To assess if miR-223 affected macrophages development and homeostasis in miR-223 KO mice, we analyzed the macrophages from peritoneal cavity and BMDMs as well. In comparison with WT mice, the percentage of macrophages from miR-223 KO mice was significantly down-regulated, whereas the percentage of BMDMs was similar. Besides, the phagocytosis of macrophages was comparable between miR-223 KO mice and WT mice. Collectively, those data suggested that miR-223 was required for macrophage homeostasis, but not development and phagocytosis.

It is well known that acute arthritis is a clinical manifestation of gout and includes the following clinical features: ${ }^{29}$ Severe pain, redness, warmth, swelling, and disability. Firstly, we evaluated the clinical phenotype of the foot pad and ankle joint models in miR-223 KO mice in vivo which mimic acute gouty arthritis in humans. Our findings showed that a significant inflammatory response induced by MSU was observed in the foot pad and ankle models in miR-223 KO mice. Neutrophils and macrophages were the major cell populations implicated in the inflammatory response in gout. ${ }^{27,30,31}$ When the inflammatory response was triggered by MSU at a local site, proinflammatory cytokines and chemokines were quickly released to recruit more neutrophil and macrophage/monocyte infiltration at the inflammatory site. According to the literature, ${ }^{32}$ pro-inflammatory cytokines, such as IL-1 $\beta$, IL- 6 and TNF- $\alpha$, were elevated within $2 \mathrm{~h}$ and peak at 4 h. The air pouch and peritoneal cavity models ${ }^{32,33}$ were used to identify the cellular phenotype in miR-223 deficient mice. Our analyses revealed that deletion of miR-223 
recruited more infiltrating neutrophils to the inflammatory site and produced more cytokines. These data verified that miR-223 deficiency could obviously give rise to enhancement of gouty inflammation in vivo.

The modulatory mechanisms of gout were determined to understand and regulate gouty flares. At the early stage of MSU crystals-triggered inflammatory response, proinflammatory mediators from macrophages were activated and released, and then participated in the acute attack process. ${ }^{32,33}$ It was reported in a previous in vitro study that miR-223 can attenuate IL-1 $\beta$ secretion through inhibition of NLRP3 inflammasome activity, ${ }^{11}$ suggesting that miR-223 could be a modulator of NLRP3 inflammasome signaling pathway involved in the pathogenesis of gouty inflammation. In our in vitro study, TNF- $\alpha$ mRNA and protein levels from miR-223 KO BMDMs increased markedly compared with WT mice. However, there were no alterations in crucial genes related to the pro-inflammatory cytokines involved in the two signaling pathways of gouty inflammation. Based on the miRBase database and previous studies, ${ }^{11,22}$ NLRP3, which is one of the potential target genes of miR-223 by binding to the 3 '-UTR in both humans and mice, was validated. ${ }^{12,13}$ We found that NLRP3 protein increased in miR-223 KO compared with WT BMDMs treated with MSU, while NLRP3 mRNA showed comparable changes. Consistent with the two emerging studies that the miR-223 was involved in the regulation of gouty inflammation via targeting NLRP3 in vitro functional experiment, ${ }^{12,13}$ our findings demonstrated that deletion of miR-223 exacerbated MSUinduced inflammatory response by targeting NLRP3, and alleviating the specific inhibition of NLRP3 inflammasome activity.

In patients with gout, low miR-223 level was observed in PBMCs from those with both acute gout and intercritical gout. Consistent with the observation that miR-223 deficiency was associated with an increase in the MSUinduced inflammation, a reduced miR-223 level in PBMCs from $\mathrm{HC}$ was observed following treatment with MSU crystals in vitro, in parallel with increased NLRP3 and IL-1 $\beta$.

There are some limitations associated with the current study. Firstly, in addition to miR-223 KO mice, we should have determined the phenotype of miR-223 knock-in mice

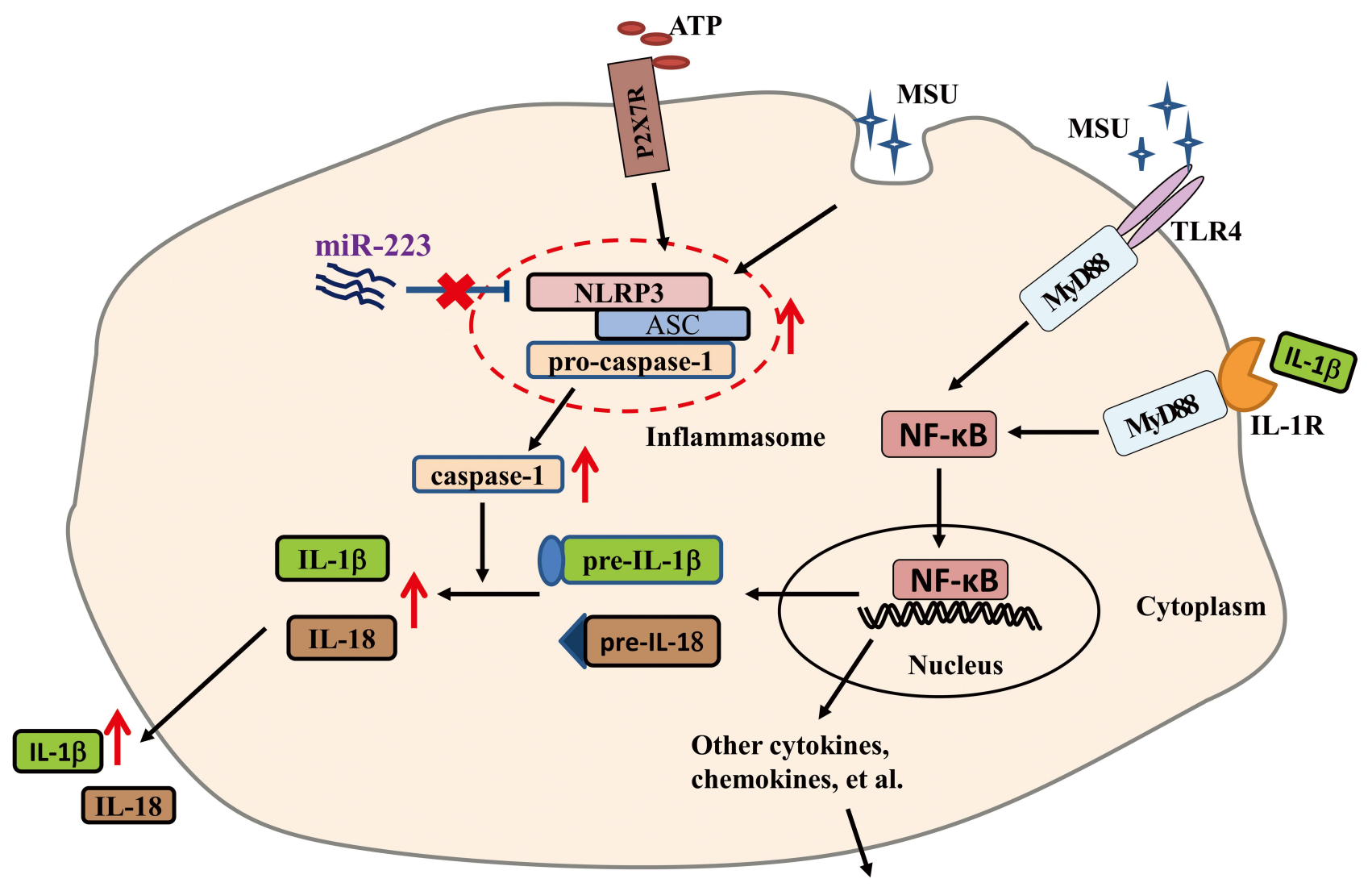

Figure 8 The schematic diagram shows that miR-223 deficiency exacerbates acute inflammatory response to monosodium urate crystals by targeting NLRP3. 
in vivo. Secondly, based on validated targets of miR-223 in literature review described, ${ }^{10}$ whether miR-223 targeting critical candidate genes in the gouty inflammatory response could target other different genes, such as TLR $4,{ }^{34}$ should have been explored. Thirdly, more research is necessary to determine the role of miR-223 in the regulatory mechanism of gouty inflammation in gout patients considering that the entire human body is composed of many complicated and sophisticated organs and is also modulated under the accurate surveillance of immune cells.

\section{Conclusion}

In this study, we revealed that miR-223 was downregulated in gout patients and miR-223 deficiency exacerbated inflammatory response in diverse murine models. These findings from humans and mice indicate that miR223 deficiency exacerbated the acute inflammatory response to MSU crystals by targeting NLRP3 (Figure 8). Therefore, up-regulation of miR-223 may serve as a potential therapeutic strategy for MSU crystal-induced acute gouty inflammation.

\section{Acknowledgments}

This work was supported by National Natural Science Foundation of China (81670801, 81800716), Sichuan Science and Technology Program (2017JY0037, 2018JY0498), Henry Ford Health System Research Grants for Immunology Program (T71016), Sichuan Medical Association (S16027), Sichuan Provincial Human Resources and Social Security Department (No.74).

\section{Disclosure}

The authors have declared no conflict of interest.

\section{References}

1. Martinon F, Petrilli V, Mayor A, Tardivel A, Tschopp J. Goutassociated uric acid crystals activate the NALP3 inflammasome. Nature. 2006;440(7081):237-241. doi:10.1038/nature04516

2. Chen CJ, Shi Y, Hearn A, et al. MyD88-dependent IL-1 receptor signaling is essential for gouty inflammation stimulated by monosodium urate crystals. $J$ Clin Invest. 2006;116(8):2262-2271. doi: $10.1172 / \mathrm{JCI} 28075$

3. Qing YF, Zhang QB, Yang QB, Xie WG, Zhou JG. Altered expression of NLRP3 inflammasome in peripheral blood from gout patients migh be associated with gouty arthritis. Gout Hyperuricemia. 2014;1 (1):25-32.

4. Qing YF, Zhang QB, Zhou JG, Jiang L. Changes in toll-like receptor (TLR)4-NFkappaB-IL1beta signaling in male gout patients might be involved in the pathogenesis of primary gouty arthritis. Rheumatol Int. 2014;34(2):213-220. doi:10.1007/s00296-013-2856-3
5. Kingsbury SR, Conaghan PG, McDermott MF. The role of the NLRP3 inflammasome in gout. J Inflamm Res. 2011;4:39-49. doi:10.2147/JIR.S11330

6. Martin WJ, Harper JL. Innate inflammation and resolution in acute gout. Immunol Cell Biol. 2010;88(1):15-19. doi:10.1038/icb.2009.89

7. Ambros V. The functions of animal microRNAs. Nature. 2004;431 (7006):350-355. doi:10.1038/nature02871

8. Bartel DP. MicroRNAs: genomics, biogenesis, mechanism, and function. Cell. 2004;116(2):281-297. doi:10.1016/S0092-8674(04) 00045-5

9. He X, Jing Z, Cheng G. MicroRNAs: new regulators of toll-like receptor signalling pathways. Biomed Res Int. 2014;2014:945169. doi:10.1155/2014/945169

10. Haneklaus M, Gerlic M, O’Neill LA, Masters SL. miR-223: infection, inflammation and cancer. J Intern Med. 2013;274(3):215-226. doi:10.1111/joim.12099

11. Haneklaus M, Gerlic M, Kurowska-Stolarska M, et al. Cutting edge: miR-223 and EBV miR-BART15 regulate the NLRP3 inflammasome and IL-1beta production. J Immunol. 2012;189(8):3795-3799. doi:10.4049/jimmunol.1200312

12. Wang X, Chi J, Dong B, et al. MiR-223-3p and miR-22-3p inhibit monosodium urate-induced gouty inflammation by targeting NLRP3. Int J Rheum Dis. 2021;24(4):599-607. doi:10.1111/1756-185X.14089

13. Tian J, Zhou D, Xiang L, et al. MiR-223-3p inhibits inflammation and pyroptosis in monosodium urate-induced rats and fibroblast-like synoviocytes by targeting NLRP3. Clin Exp Immunol. 2021. doi:10.1111/cei.13587

14. Wallace SL, Robinson H, Masi AT, Decker JL, McCarty DJ, Yu TF. Preliminary criteria for the classification of the acute arthritis of primary gout. Arthritis Rheum. 1977;20(3):895-900. doi:10.1002/ art. 1780200320

15. Johnnidis JB, Harris MH, Wheeler RT, et al. Regulation of progenitor cell proliferation and granulocyte function by microRNA-223. Nature. 2008;451(7182):1125-1129. doi:10.1038/nature06607

16. Getting SJ, Christian HC, Flower RJ, Perretti M. Activation of melanocortin type 3 receptor as a molecular mechanism for adrenocorticotropic hormone efficacy in gouty arthritis. Arthritis Rheum. 2002;46(10):2765-2775. doi:10.1002/art.10526

17. Vyleta ML, Wong J, Magun BE. Suppression of ribosomal function triggers innate immune signaling through activation of the NLRP3 inflammasome. PLoS One. 2012;7(5):e36044. doi:10.1371/journal. pone. 0036044

18. Torres R, Macdonald L, Croll SD, et al. Hyperalgesia, synovitis and multiple biomarkers of inflammation are suppressed by interleukin 1 inhibition in a novel animal model of gouty arthritis. Ann Rheum Dis. 2009;68(10):1602-1608. doi:10.1136/ard.2009.109355

19. Ryckman C, McColl SR, Vandal K, et al. Role of S100A8 and $\mathrm{S} 100 \mathrm{~A} 9$ in neutrophil recruitment in response to monosodium urate monohydrate crystals in the air-pouch model of acute gouty arthritis. Arthritis Rheum. 2003;48(8):2310-2320. doi:10.1002/art.11079

20. Jin HM, Kim T-J, Choi J-H, et al. MicroRNA-155 as a proinflammatory regulator via SHIP-1 down-regulation in acute gouty arthritis. Arthritis Res Ther. 2014;16(2):R88. doi:10.1186/ $\operatorname{ar} 4531$

21. McGettrick AF, O'Neill LA. NLRP3 and IL-1beta in macrophages as critical regulators of metabolic diseases. Diabetes Obes Metab. 2013;15(Suppl 3):19-25. doi:10.1111/dom.12169

22. Bauernfeind F, Rieger A, Schildberg FA, Knolle PA, Schmid-Burgk JL, Hornung V. NLRP3 inflammasome activity is negatively controlled by miR-223. J Immunol. 2012;189(8):4175-4181. doi:10.4049/jimmunol.1201516

23. Zhao G, Jiang K, Yang Y, et al. The potential therapeutic role of miR-223 in bovine endometritis by targeting the NLRP3 inflammasome. Front Immunol. 2018;9:1916. doi:10.3389/ fimmu.2018.01916 
24. Wang K, Long B, Liu F, et al. A circular RNA protects the heart from pathological hypertrophy and heart failure by targeting miR-223. Eur Heart J. 2016;37(33):2602-2611. doi:10.1093/eurheartj/ehv713

25. Ray A, Dittel BN. Isolation of mouse peritoneal cavity cells. J Vis Exp. 2010;35.

26. Zheng SC, Zhu XX, Xue Y, et al. Role of the NLRP3 inflammasome in the transient release of IL-1beta induced by monosodium urate crystals in human fibroblast-like synoviocytes. $J$ Inflamm. 2015;12:30. doi:10.1186/s12950-015-0070-7

27. Mankan AK, Dau T, Jenne D, Hornung V. The NLRP3/ASC/ Caspase-1 axis regulates IL-1beta processing in neutrophils. Eur J Immunol. 2012;42(3):710-715. doi:10.1002/eji.201141921

28. Yang QB, He YL, Zhang QB, Mi QS, Zhou JG. Downregulation of transcription factor T-bet as a protective strategy in monosodium urate-induced gouty infLammation. Front Immunol. 2019;10:1199. doi:10.3389/fimmu.2019.01199

29. Perez-Ruiz F, Castillo E, Chinchilla SP, Herrero-Beites AM. Clinical manifestations and diagnosis of gout. Rheum Dis Clin North Am. 2014;40(2):193-206. doi:10.1016/j.rdc.2014.01.003
30. Amaral FA, Costa VV, Tavares LD, et al. NLRP3 inflammasome-mediated neutrophil recruitment and hypernociception depend on leukotriene $\mathrm{B}(4)$ in a murine model of gout. Arthritis Rheum. 2012;64(2):474-484. doi:10.1002/art.33355

31. Mitroulis I, Kambas K, Ritis K. Neutrophils, IL-1beta, and gout: is there a link? Semin Immunopathol. 2013;35(4):501-512. doi:10.1007/s00281-013-0361-0

32. Martin WJ, Walton M, Harper J. Resident macrophages initiating and driving inflammation in a monosodium urate monohydrate crystal-induced murine peritoneal model of acute gout. Arthritis Rheum. 2009;60(1):281-289. doi:10.1002/art.24185

33. Liu-Bryan R, Scott P, Sydlaske A, Rose DM, Terkeltaub R. Innate immunity conferred by toll-like receptors 2 and 4 and myeloid differentiation factor 88 expression is pivotal to monosodium urate monohydrate crystal-induced inflammation. Arthritis Rheum. 2005;52 (9):2936-2946. doi:10.1002/art.21238

34. Wang J, Bai X, Song Q, et al. miR-223 inhibits lipid deposition and inflammation by suppressing toll-like receptor 4 signaling in macrophages. Int $J$ Mol Sci. 2015;16(10):24965-24982. doi:10.3390/ijms 161024965
Journal of Inflammation Research

\section{Publish your work in this journal}

The Journal of Inflammation Research is an international, peerreviewed open-access journal that welcomes laboratory and clinical findings on the molecular basis, cell biology and pharmacology of inflammation including original research, reviews, symposium reports, hypothesis formation and commentaries on: acute/chronic inflammation; mediators of inflammation; cellular processes; molecular mechanisms; pharmacology and novel anti-inflammatory drugs; clinical conditions involving inflammation. The manuscript management system is completely online and includes a very quick and fair peerreview system. Visit http://www.dovepress.com/testimonials.php to read real quotes from published authors. 